
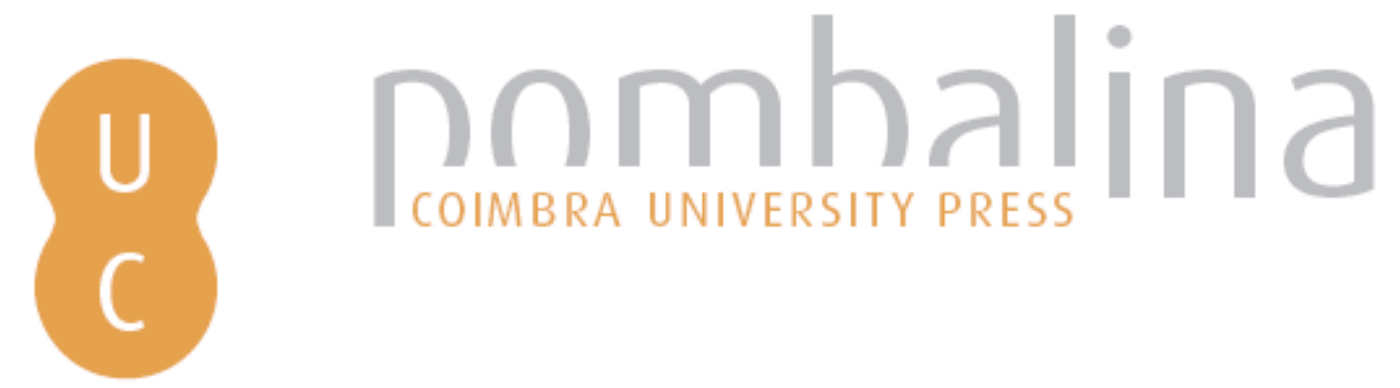

\title{
O sistema alimentar da cidade do Rio de Janeiro no século XVIII: um estudo arqueológico de restos faunísticos
}
Autor(es):
Locks, Martha; Lima, Tania Andrade
Publicado por: Imprensa da Universidade de Coimbra
URL
persistente:
URI:http://hdl.handle.net/10316.2/45254
DOI:
DOI:https://doi.org/10.14195/978-989-26-1720-6_14
Accessed : $\quad$ 26-Apr-2023 14:47:27

A navegação consulta e descarregamento dos títulos inseridos nas Bibliotecas Digitais UC Digitalis, UC Pombalina e UC Impactum, pressupõem a aceitação plena e sem reservas dos Termos e Condições de Uso destas Bibliotecas Digitais, disponíveis em https://digitalis.uc.pt/pt-pt/termos.

Conforme exposto nos referidos Termos e Condições de Uso, o descarregamento de títulos de acesso restrito requer uma licença válida de autorização devendo o utilizador aceder ao(s) documento(s) a partir de um endereço de IP da instituição detentora da supramencionada licença.

Ao utilizador é apenas permitido o descarregamento para uso pessoal, pelo que o emprego do(s) título(s) descarregado(s) para outro fim, designadamente comercial, carece de autorização do respetivo autor ou editor da obra.

Na medida em que todas as obras da UC Digitalis se encontram protegidas pelo Código do Direito de Autor e Direitos Conexos e demais legislação aplicável, toda a cópia, parcial ou total, deste documento, nos casos em que é legalmente admitida, deverá conter ou fazer-se acompanhar por este aviso.

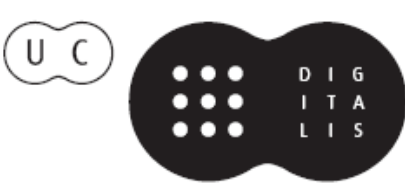


Carmen Soares

\section{Cilene da Silva Gomes Ribeiro}

\section{(coords.)}

MESAS

\section{ALIMENTAÇÃ O, SAÚDE \& CULTURA}

\section{IU LUO-BRASILEIRAS}

\section{VOLUME II}

IMPRENSA DA UNIVERSIDADE DE COIMBRA

COIMBRA UNIVERSITY PRESS

PUCPRESS 


\title{
O sistema Alimentar da CidAde do Rio de Janeiro no século XVIII
}

\author{
(The food system in $18^{\text {th }}$ century \\ Rio de Janeiro)

\section{UM ESTUDO ARQUEOLÓgICO DE RESTOS FAUNÍSTICOS}

\author{
(An archaeological study \\ of faunal remains)
}

\author{
Martha Locks \\ Museu Nacional / Universidade Federal do Rio \\ de Janeiro, Departamento de Antropologia \\ MLOCKS@MN.UFRJ.BR
}

Tania Andrade Lima

Museu Nacional / Universidade Federal do Rio de Janeiro TALIMA8@GMAIL.com

\begin{abstract}
Resumo: Este artigo discute os restos faunísticos encontrados nas escavações arqueológicas realizadas à Rua da Assembleia, no centro histórico do Rio de Janeiro, com destaque para os ossos de bovinos. Correspondendo a diferentes cortes de carne com valores de mercado diferenciados, esses restos são atribuídos aos distintos estratos sociais que ocupavam a região no século XVIII. Contudo, chamou a atenção, em meio aos demais, a alta frequência de ossos do crânio, além de chifres, levantando-se a possibilidade do consumo de cabeças de boi, à época, por escravos urbanos.

Palavras-chave: alimentação, Rio de Janeiro, restos faunísticos, cabeça de boi, século XVIII.
\end{abstract}

Aвstract: This article discusses the faunal remains found in the archaeological excavations undertaken in Rua da Assembleia, in Rio de Janeiro's downtown, highlighting cattle bones in particular. Corresponding to different cuts of meat with distinct market prices, these remains are attributed to the different social strata who occupied the region in the eighteenth century. However, attention was drawn to the high frequency of skull bones found among them, as well horns, raising the possibility of the consumption of cow heads by urban slaves during the period.

KeYwords: food, Rio de Janeiro, faunal remains, cow skull bones, $18^{\text {th }}$ century. 
No sítio arqueológico da Rua da Assembleia descrito anteriormente, foram encontrados inúmeros fragmentos de ossos do esqueleto axial e apendicular de mamíferos e aves, correspondendo principalmente a espécies domésticas (bovinos, suínos, ovinos, canídeos, felinos e galináceos). Além deles, foram recuperados uma vértebra de cetáceo, diversos peixes e moluscos, totalizando cerca de 8.000 itens, entre dentes, fragmentos de ossos e carapaças de moluscos. A maioria deles pertence à espécie Bos taurus Linnaeus, 1758 (Figura 1). Dentre os outros achados de mamíferos, foram encontrados poucos ossos de suínos (Sus sp) e ovinos (Ovis sp) (Figs. 2 e 3). O achado de ossos de cão e gato remetem à presença de animais de estimação no registro arqueológico. Quanto às aves, a espécie Gallus gallus domesticus (Linnaeus, 1748) é a mais frequente.

Por certo eles correspondem aos restos alimentares de refeições consumidas nas imediações, que foram transportados como lixo nos barrís e descartados pelos escravos na área de despejo do terreno.

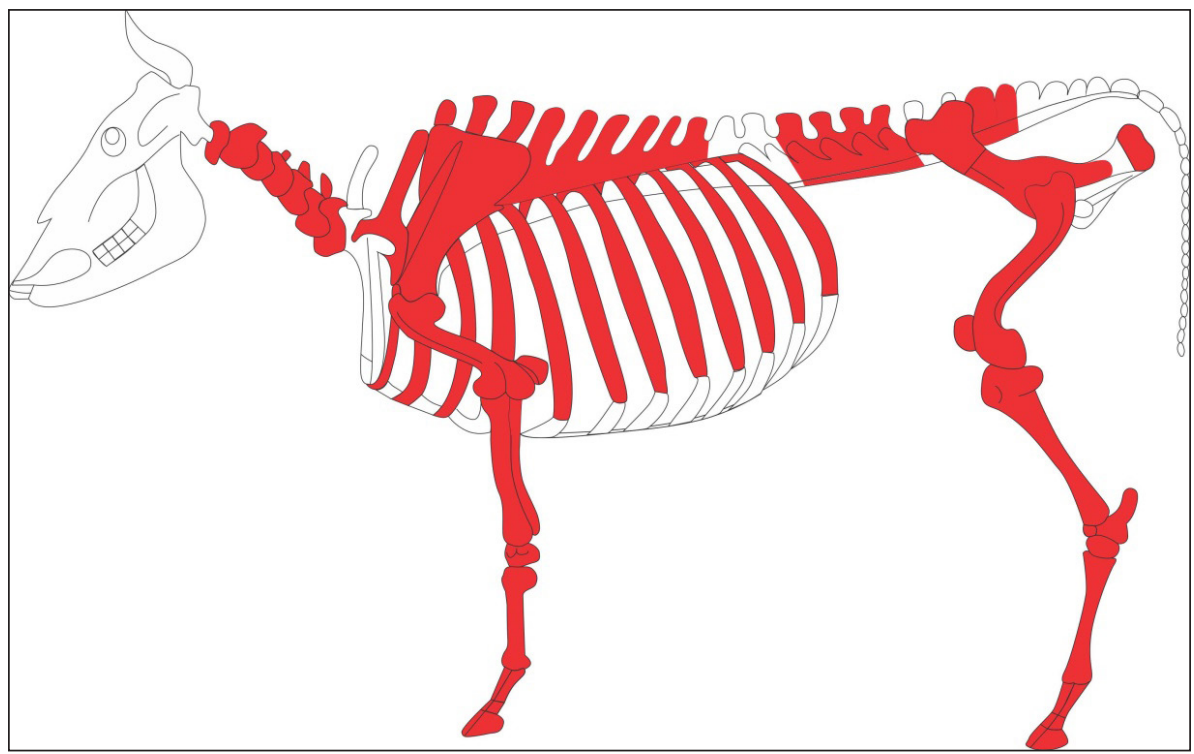

Figura 1: Em vermelho, os ossos do esqueleto pós-cranial de Bos taurus recuperados na área de despejo de lixo

Fonte: <https://ru.depositphotos.com/6194483/stock-illustration-skeleton-of-cow.html>. Desenho: Martha Locks. 


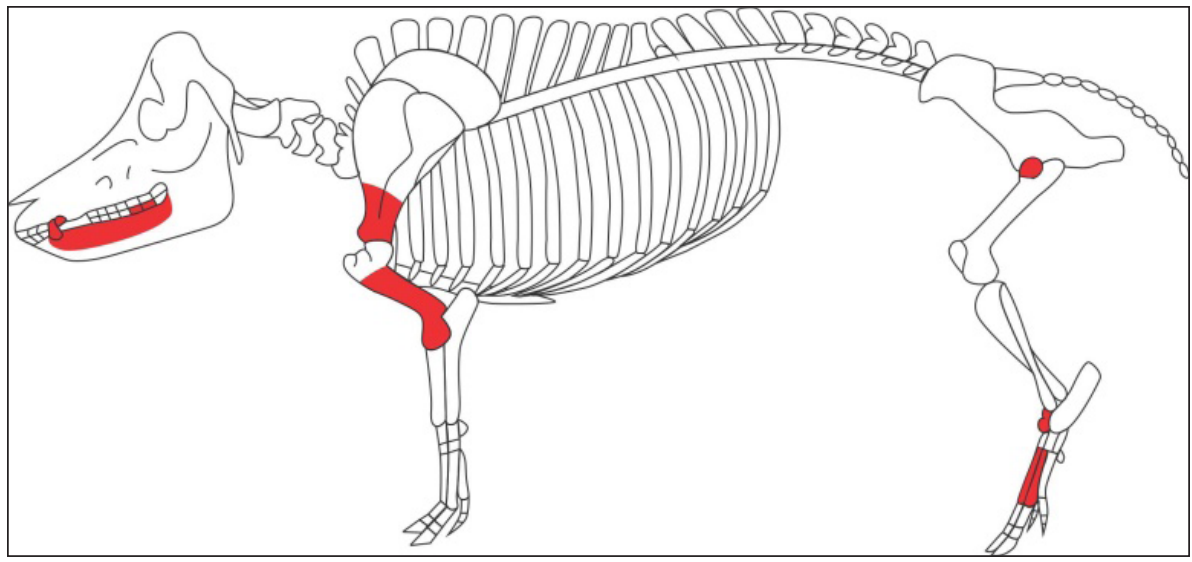

Figura 2: Os ossos encontrados de Sus sp

Fonte: <https://i.pinimg.com/originals/77/02/ff/7702ff7db73216cdb88aa3ce485d7617.png>. Desenho: Martha Locks.

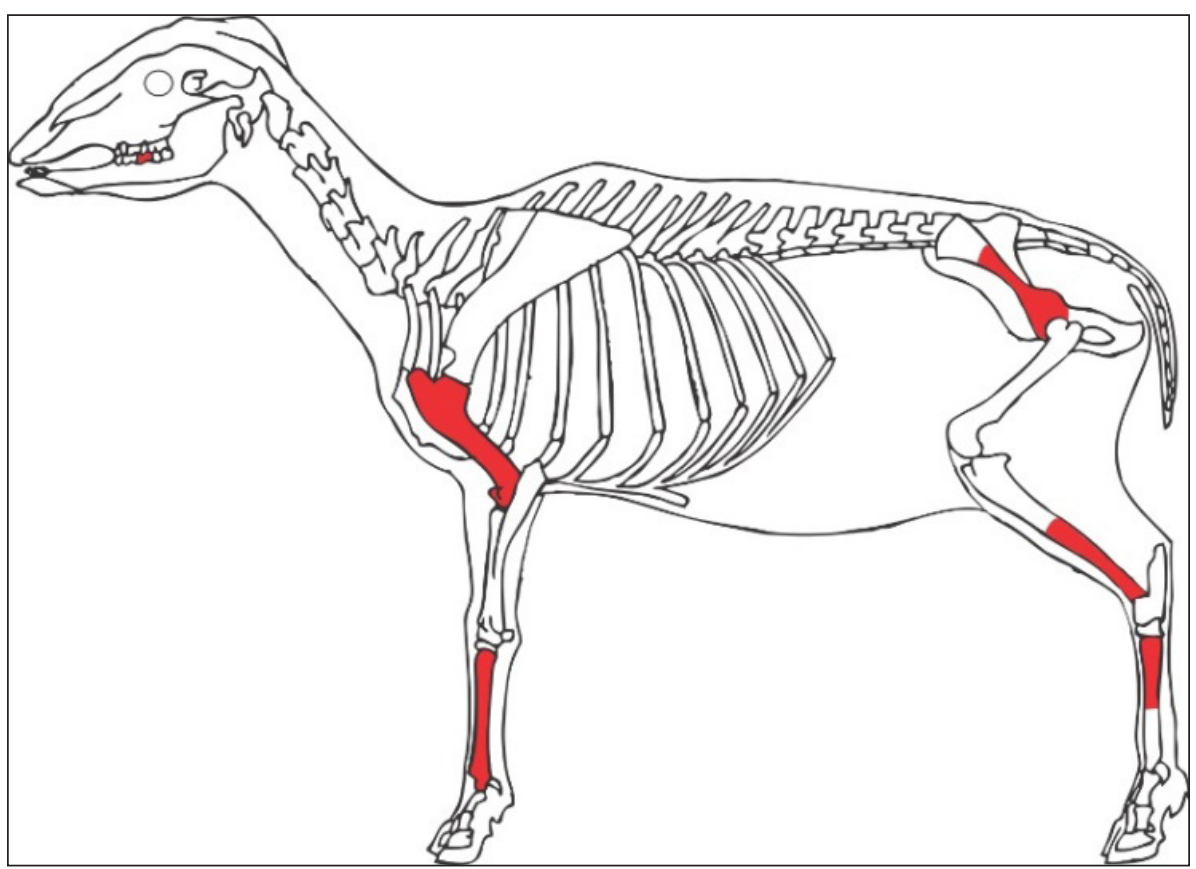

Figura 3: Os ossos recuperados de Ovis sp

Fonte: <https://www.shutterstock.com/image-vector/drawing-sheep-skeleton-101330401>. Desenho: Martha Locks 
De bovídeos foram recuperados ossos que correspondem a cortes de carne macia, considerados de alta qualidade, mas também carnes mais duras e fibrosas, de baixa qualidade, com valores de mercado diferenciados ${ }^{1}$. A amostra aponta possibilidades de consumo de amplo espectro, o que significa dizer que a lixeira continha restos tanto de segmentos abastados, quanto de segmentos menos favorecidos, ou, sobretudo, francamente desfavorecidos, como é o caso dos escravos. Neste artigo abordaremos apenas aqueles que atribuímos a estes últimos.

Chamou particularmente nossa atenção, em meio à amostra óssea analisada, a presença de diversos ossos do crânio de bovinos, entre eles cornos e mandíbulas, que, tanto quanto se sabe, não fizeram parte da dieta dos segmentos livres da sociedade colonial do Rio de Janeiro, sobretudo por se tratar, como indicam os chifres, de cabeças inteiras.

Em análise preliminar, foram encontrados 589 fragmentos do crânio de bovídeos, correspondentes a ossos (incluindo o processo cornual) e dentes. Os ossos encontram-se muito fragmentados porque o crânio desses animais é constituído por ossos pneumáticos. Ocos e apresentando câmaras de ar internas, de modo a tornar a cabeça mais leve, eles são pouco resistentes, o que dificulta sua preservação no registro arqueológico.

\begin{tabular}{|c|c|}
\hline Peças do crânio recuperadas & Quant. \\
\hline Dentes & 331 \\
\hline Fragmentos de ossos & 258 \\
\hline Total & 589 \\
\hline
\end{tabular}

Tabela 1: Total de dentes e ossos do crânio de B. taurus recuperados

\begin{tabular}{|c|c|}
\hline Fragmentos de ossos do crânio & Quantidade \\
\hline Mandíbula & 172 \\
\hline Processo cornual & 41 \\
\hline Frontal & 20 \\
\hline Ossos diversos da caixa craniana & 16 \\
\hline Maxilar & 3 \\
\hline Esfenóide & 2 \\
\hline Côndilo Occipital & 1 \\
\hline Orbital & 1 \\
\hline Temporal & 1 \\
\hline Processo Zigomático & 1 \\
\hline Total & 258 \\
\hline
\end{tabular}

Tabela 2: Total de fragmentos de ossos do crânio de B. taurus recuperados 
Já a mandíbula e os dentes são os mais representados na amostra. Os dentes, que são as estruturas mais resistentes do crânio em função da sua composição, foram os encontrados em maior número e em grande parte completos, em especial os molariformes inferiores, por conta de sua morfologia.

\begin{tabular}{|c|c|c|c|c|}
\hline Posição anatômica dos dentes & Esquerdo & Direito & Indeterm. & Total \\
\hline Dentes inferiores & 110 & 80 & 3 & 193 \\
\hline Dentes superiores & 77 & 53 & 3 & 133 \\
\hline Fragmentos de molariformes & 0 & 0 & 5 & 5 \\
\hline Total & 187 & 133 & 11 & 331 \\
\hline
\end{tabular}

Tabela 3: Quantidade de dentes superiores, inferiores e fragmentos de molariformes indeterminados de B. taurus

\begin{tabular}{|c|c|c|c|c|}
\hline Posição anatômica dentes superiores & Esquerdo & Direito & Indeterm. & Total \\
\hline M1 & 22 & 16 & - & 38 \\
\hline $\mathrm{Pm} 4$ & 17 & 8 & - & 25 \\
\hline M2 & 16 & 10 & - & 26 \\
\hline M3 & 11 & 6 & - & 17 \\
\hline $\mathrm{dPm} 4$ & 5 & 5 & - & 10 \\
\hline Pm3 & 4 & 3 & - & 7 \\
\hline $\operatorname{Pm} 2$ & 1 & 2 & - & 3 \\
\hline Fragmentos de molariformes & 1 & 3 & 3 & 7 \\
\hline Total & 77 & 53 & 3 & 133 \\
\hline
\end{tabular}

Tabela 4: Quantidade de dentes molariformes superiores de B. taurus quanto à posição anatômica, sendo d correspondente a dente decíduo

\begin{tabular}{|c|c|c|c|c|}
\hline Posição anatômica dos dentes inferiores & Esquerdo & Direito & Indeterm. & Total \\
\hline M1 & 29 & 21 & - & 50 \\
\hline M3 & 25 & 19 & - & 44 \\
\hline M2 & 24 & 15 & - & 39 \\
\hline Pm4 & 11 & 9 & - & 20 \\
\hline Pm3 & 9 & 10 & - & 19 \\
\hline I2 & 5 & 2 & - & 7 \\
\hline I1 & 4 & 1 & - & 5 \\
\hline dPm4 & 1 & 1 & - & 2 \\
\hline Pm2 & 1 & 2 & - & 3 \\
\hline I3 & 1 & - & - & 1 \\
\hline Fragmentos & - & - & 3 & 3 \\
\hline Total & 110 & 80 & 3 & 193 \\
\hline
\end{tabular}

Tabela 5: Quantidade de dentes inferiores de B. taurus quanto à posição anatômica 
As peças recuperadas de crânios de boi não deixam dúvidas quanto à presença de cabeças inteiras no registro arqueológico, tendo sido quantificado um número mínimo de 29 cabeças, a partir dos primeiros molares inferiores esquerdos. Essa posição é fortalecida pelo fato de não terem sido encontradas marcas de corte ou descarnamento nos ossos do crânio, sugerindo que a cabeça foi assada ou cozida inteira, retirando-se os bocados de carne no momento do consumo, sem a utilização de instrumentos cortantes. Essas marcas, feitas com objetos cortantes, foram encontradas em alguns poucos casos apenas na mandíbula, área de musculatura mais forte, e no osso hióide, sugerindo a extração da língua para consumo.

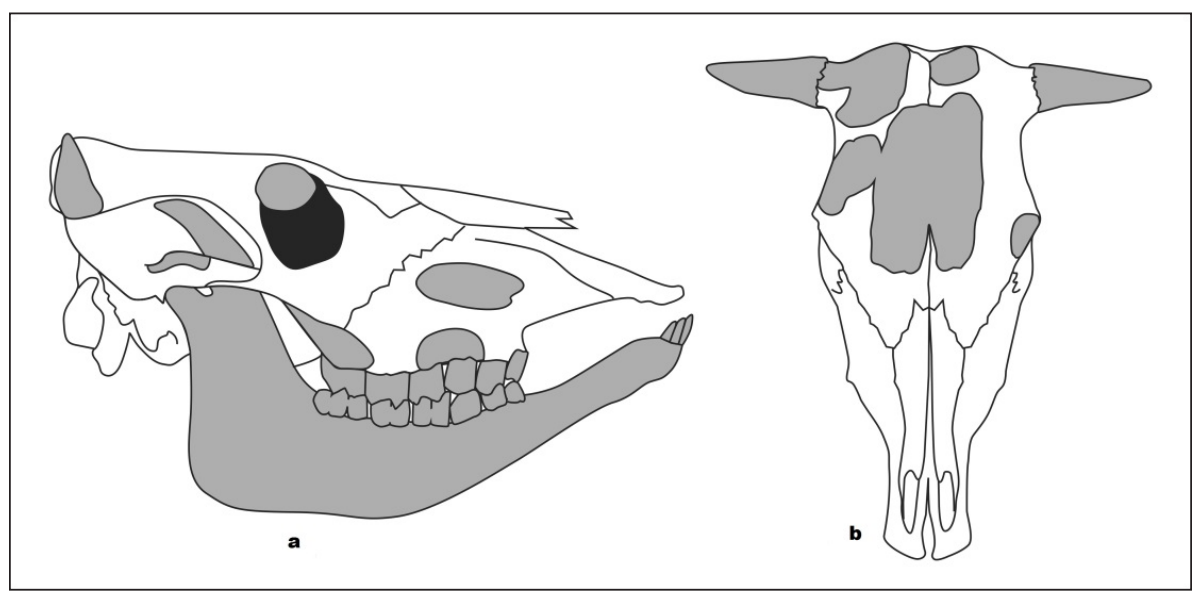

Figura 4: Vista lateral (a) e dorsal (b) do crânio de B. taurus Nota: Em cinza, os ossos encontrados pela pesquisa.

Fonte:Adaptado de <http://zootecniaufms.blogspot.com/2012/04/anatomia-ossos-cranio-bovino.html>.

Desenho: Martha Locks

\section{i. O consumo de CABEÇa de boi no Rio de Janeiro colonial}

Este achado conduziu necessariamente a uma investigação sobre a possibilidade do consumo de cabeças de boi no Brasil colonial. Foram considerados como possíveis fontes de informação livros de receitas de época e relatos de viajantes que passaram pelo Rio, quer retratando o cotidiano, quer anotando práticas que lhes pareciam peculiares ou curiosas.

Não foram encontradas referências ao consumo de cabeça de boi na Arte de Cozinha, de 1680, de Domingos Rodrigues, nem em o Cozinheiro Moderno, de 1780, de Rigaud, embora tenham triplicado as receitas de carne de vaca, sob forte influência da culinária francesa, que já ultrapassara a essa altura as 
práticas do medievo, primado das caças, como cervídeos, javalis, perdizes, etc. Porém surgem receitas, embora muito poucas, para miolos e paladares de vaca. Ao final, portanto, do século XVII e primeira metade do XVIII, à luz dos livros de receitas, o modelo alimentar transportado da metrópole para o Rio de Janeiro era o da Arte de Cozinha, sem qualquer referência ao consumo de cabeça de boi, exceto por parcas indicações de receitas de língua e miolos, partes que podiam ser retiradas e comercializadas separadamente do restante. Já a varredura feita na literatura dos viajantes, escassa para o período estudado, localizou apenas duas referências em Debret, mas já nas primeiras décadas do século XIX: uma, à oferta filantrópica feita diariamente a presos, pela Santa Casa da Misericórdia, de "dois enormes caldeirões de sopa feita com cabeças de bois reservadas especialmente para esse fim, e mais um suplemento de farinha de mandioca”, já que a legislação portuguesa em vigor no Brasil à época desobrigava o Governo de alimentá-los. E outra, às negras que vendiam angu na rua para outros negros (angu é uma massa de farinha de milho muito consumida no Brasil). Assim relata Debret:

É na classe das negras livres que se encontram as cozinheiras vendedoras de angus [...]. Compõe-se, no seu mais alto grau de requinte, de diversos pedaços de carne, coração, fígado, bofe, língua, amídalas e outras partes da cabeça, à exceção do miolo, cortados miúdos e aos quais se ajuntam água, banha de porco, azeite de dendê, quiabos e temperos variados; o conjunto é cozido até adquirir a consistência necessária ${ }^{2}$.

Ou seja, a esse tempo, cabeça de boi era um tipo de alimento destinado à escória da sociedade, no caso, prisioneiros e africanos, sendo possível supor que não fosse diferente nas décadas precedentes.

2 Debret 1940 (grifos nossos). 


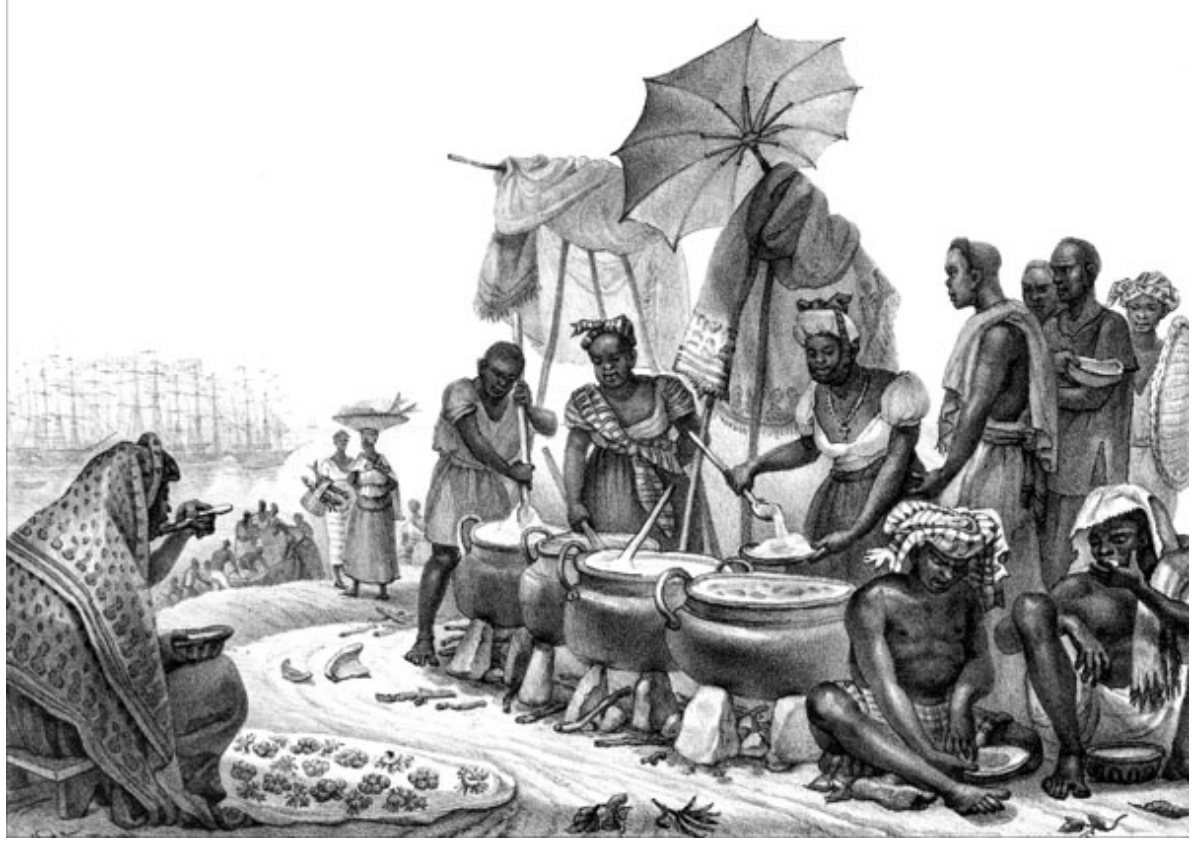

Figura 5: Negras vendedoras de angu, feito com pedaços de cabeça de boi, entre outros ingredientes, para outros negros

Fonte: Aquarela de Debret, datada entre 1816 e $1831^{3}$.

Cumpre destacar que o matadouro e açougue público ficavam muito próximos do terreno estudado, de tal forma que cabeças de boi podiam ser facilmente obtidas à época ${ }^{4}$. Assim, considerando ser o sítio estudado um local de trabalho de escravos, onde eles se reuniam constantemente, levantamos a hipótese, em vista da dificuldade desses indivíduos contarem com carne fresca na sua dieta, que lhes era negada por conta do seu custo elevado, de eles terem encontrado uma alternativa na cabeça de boi, uma rica fonte proteica desprezada pelos demais segmentos da sociedade do Rio de Janeiro. Considerando que o registro documental do período em questão nada informa quanto a essa possibilidade, investigamos o consumo de cabeça de boi na atualidade, como uma possível sobrevivência de práticas muito recuadas. Se nos grandes centros urbanos ele é impensável hoje em dia, inexistindo oferta quer da cabeça inteira, quer de seus componentes retalhados (exceção feita

\footnotetext{
$3 \quad$ Bandeira, Lago 2009: 196.

4 Coaracy 1988; Abreu 2010: 384-5; Vieira Fazenda 2011a [1923]: 198; Vieira Fazenda 2011b [1924]: 639; Tavares 2012: 59.
} 
apenas à língua que continua sendo de fácil aquisição), desviamos o foco para áreas periféricas, onde foi possível obter informações mais consistentes.

\section{O CONSUMO DE CABEÇA DE BOI NA ATUALIDAdE}

Em 2012, em viagem feita ao sertão da Bahia para registrar uma das piores secas dos últimos trinta anos, a agência Reuters, documentou, com evidente estranhamento, o preparo de uma cabeça de boi cozida em um velho caldeirão de alumínio, numa casa modesta em Maracás. Os moradores da região sofrem de anemia, raramente consomem proteína animal, e a cabeça de boi constitui uma de suas poucas alternativas. Como a base econômica do município é predominantemente a pecuária bovina extensiva para corte, provavelmente as cabeças são descartadas no abate e aproveitadas para consumo pela população desprovida e sem recursos.

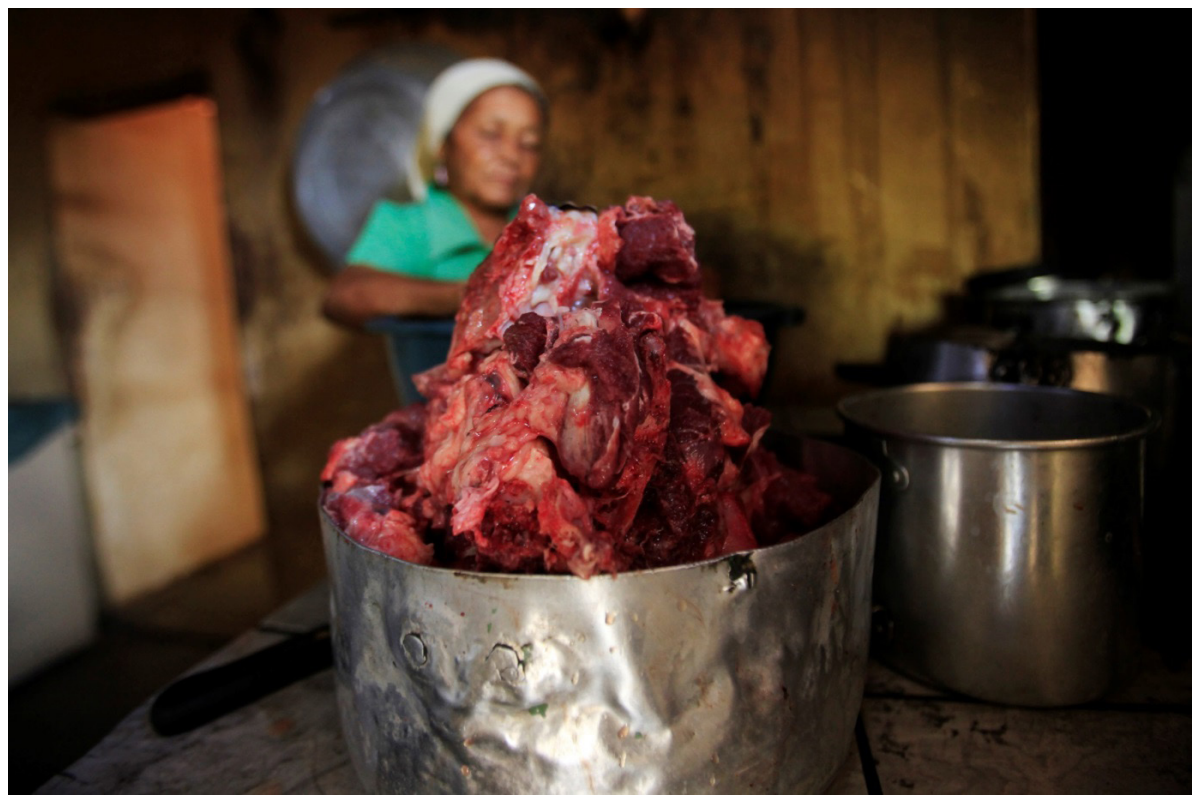

Figura 6: Preparo de cabeça de boi em caldeirão de alumínio, no interior da Bahia Foto: Agência Reuters.

No Maranhão, nos festejos tradicionais do bumba meu boi, onde se mesclam tradições africanas, indígenas e europeias, o núcleo principal em torno do qual se desenvolve a história, é a negra escrava Catirina; grávida, ela pede ao seu marido Chico, também escravo, uma língua de boi para comer. Para satisfazê-la, ele mata um animal da fazenda, cujo dono o manda prender, sendo o boi posteriormente ressucitado por curandeiros. Nesse 
contexto da festa, foi registrado, em Soledade, o consumo da cabeça de boi pelos moradores locais, negros.

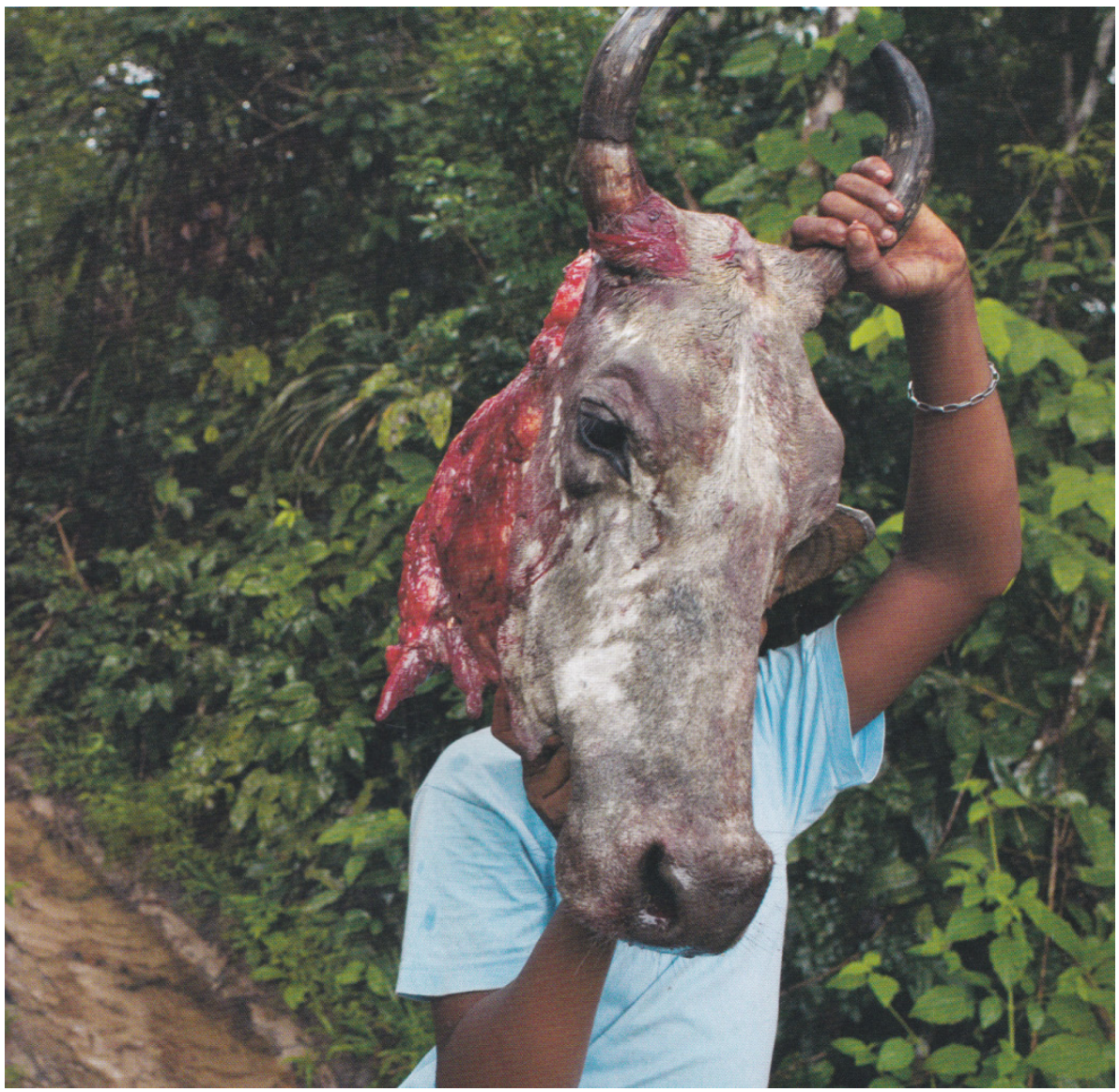

Figura 7: Consumo de cabeça de boi nos festejos do Bumba meu boi, Maranhão Foto: Tyrone Turner, para National Geographic ${ }^{5}$.

Também no Maranhão, foi documentado o consumo de cabeça de boi, em Riachão ${ }^{6}$. Nessa localidade, a cabeça é bem temperada, colocada no interior de uma lata grande de tinta de 18 litros, e levada a assar em um buraco no chão, com brasas no seu interior. Porém, é em Mato Grosso, estado onde a agropecuária é a principal atividade econômica, que a cabeça de boi constitui um prato típico regional e tradicional, servido inclusive em

\footnotetext{
Mann, Hecht 2012.

6 Disponível em: <www.tocnoticias.com.br/ler_noticia.php?idnoticia=477>, Acesso em: 18 jul. 2015.
} 
alguns restaurantes que chegam a oferecê-la gratuitamente ${ }^{7}$. Ela é preparada de diferentes maneiras, mas sempre como um empreendimento coletivo, em reuniões realizadas em chácaras ou sítios, e partilhada festivamente entre os presentes. Em Várzea Grande, no último sábado do mês são servidas dez cabeças de boi, gratuitamente, assadas em forno rústico de tijolo e barro, a lenha. O segredo do seu preparo é lavar muito bem as peças a serem assadas ${ }^{8}$.

Outra forma de preparar a cabeça de boi em Mato Grosso é no tacho, sobre fogo alto a lenha, onde ela permanece cozinhando por oito horas sem nenhum tempero, nem mesmo sal. Uma vez cozida, é posta à mesa com molho vinagrete, pimenta, farinha e mandioca, servidos à parte 9 . Já em Manso, a cabeça é assada no chão, em uma cova retangular, com brasas, diretamente na terra. A cova é recoberta por chapas de ferro, na verdade trempes de fogão a lenha, que asseguram a temperatura elevada no seu interior ${ }^{10}$.

Nossa investigação se estendeu, além do consumo da cabeça inteira, ao consumo dos seus retalhos. Em princípio, tudo na cabeça é comestível. Além da língua - sem dúvida a parte mais cotada, embora não sejam muitos os que a comem - há os olhos, os miolos, a bochecha, o focinho, no caso, parte anterior da face, que corresponde à porção carnosa do rostro, compreendendo as narinas, parte da cartilagem nasal, lábio superior, lábio inferior e papilas bucais - aí incluído o céu da boca.

Se hoje em dia é problemático obter cabeças inteiras, algumas partes podem ser eventualmente adquiridas diretamente em matadouros ou sob encomenda, e apenas a língua pode ser facilmente comprada, inclusive em supermercados. Já os olhos, muito apreciados pelos gourmets, são tão difíceis de conseguir quanto a cabeça inteira.

A bochecha, corte tirado dos músculos da face, tem uma carne densa, magra, fibrosa, e de cocção muito lenta. Com um tecido muscular muito resistente, não deve ser frita, mas assada ao longo de muitas horas. Há indicações de até 14 horas para o seu cozimento. Pouco difundida no Brasil, é consumida, entre muitos outros países, na Inglaterra, Estados Unidos, e, mais especialmente na França, berço da gastronomia, onde todos os componentes da cabeça do boi são muito valorizados.

Já o focinho, é designado popularmente no Rio de Janeiro como matruco. Termo de origem árabe, matrucar significa esquartejar, abater reses. Embora

\footnotetext{
Disponível em: <https://saprac.wordpress.com/2008/11/12/comida-tipica/>, Acesso em: 31 jul. 2015.

8 Disponível em: <http://globotv.globo.com/tv-centro-america/e-bem-mato-grosso/v/e-bem-mt-traz-a-tradicional-cabeca-de-boi/2083768/>, Acesso em: 16 jun. 2015.
10 Disponível em: <https://www.youtube.com/watch?v=J4zjyGGBh0E〉, Acesso em: 8 jul. 2015.

Disponível em: <https://www.youtube.com/watch?v=kxMUGn3HwKM>, Acesso em: 8 jul. 2015.
} 
considerado repugnante como alimento, o matruco conta com alguns adeptos. Em pesquisa de campo feita em Maricá, na Região dos Lagos, litoral do Rio de Janeiro, que contou com muitos escravos no passado, foi observado o consumo local de matruco por algumas pessoas, direta ou indiretamente descendentes de escravos. Elas foram entrevistadas, visando obter informações sobre formas de aquisição e consumo desse retalho da cabeça de boi, raramente visto e menos ainda consumido.

O matruco é vendido em uma pequena venda de alimentos, e, segundo seu proprietário tem grande procura e aceitação local. São preparados com sal e conservantes, e comercializados como carne bovina salgada, curada e dessecada. São vendidos por preço módico, valendo aproximadamente a metade do que se cobra pela carne de baixa qualidade. É uma carne apreciada em sua própria família, segundo ele, desde sua tataravó. Sua bisavó, avó e mãe, afrodescendentes, aprenderam com os antepassados e continuam preparando matrucos até hoje, que ele define como comida de escravo.

Além de um vendedor, foi entrevistada uma consumidora de matrucos, que aprendeu a prepará-los com a mãe e a avó, pois morava junto com elas e seu avô, afrodescendente. Ela não apenas informou muito gentilmente como se prepara passo a passo o matruco, como permitiu que todas as etapas fossem fotografadas. Em primeiro lugar, lavar bem, cortar e deixar de molho para retirar o sal. Ferver para dessalgá-lo e novamente deixar de molho. Em seguida, limpar, retirando a pele, os pelos e o sebo, lavar novamente e colocar para cozinhar junto com o feijão. Assim que o feijão e a carne estiverem cozidos, temperar, e o matruco está pronto para ser servido. Mais raramente algumas poucas pessoas dizem que ele pode ser frito, contudo é mais frequentemente consumido no feijão.

Numa pesquisa realizada pelo Instituto Estadual do Patrimônio Cultural do Rio de Janeiro foi constatado o consumo de matruco em outro município, Itaguaí, tendo os moradores locais informado que "o matruco assado com feijão e angu era a 'comida dos pobres', sendo um tipo de carne pouco valorizada e adquirida nos matadouros locais, aos quais não se tem mais acesso hoje"11.

Fica claro portanto que, se nos primeiros séculos da colônia só se comia cabeça de boi em situações de privação aguda, nos tempos atuais isto se manteve, embora mais recentemente ela tenha sido apropriada como sofisticação culinária por aqueles que apreciam comidas exóticas ou que anseiam por novas experiências gastronômicas.

11 Ruas et al. 1978. 


\section{Considerações finais}

No Rio de Janeiro colonial, se os segmentos livres da população tinham preconceito contra o seu consumo, muito provavelmente antigas práticas dos africanos em seu continente de origem permitiam não somente que eles apreciassem suas partes, como soubessem prepará-las de modo a torná-las saborosas, tal como faziam as negras vendedoras de angu descritas por Debret.

Assim, entende-se aqui que sobretudo africanos escravizados comeram cabeça de boi no Rio de Janeiro setecentista. No caso do terreno estudado, 29 cabeças pode ser considerado um número expressivo, tendo em vista a quantidade de carne que elas contêm, já que uma cabeça média pode alimentar bem cerca de doze pessoas. Por sua vez, nos tempos atuais, trata-se de um consumo em grande parte direta ou indiretamente associado a afrodescendentes, como sobrevivência de uma prática muito recuada, atribuída a eles, cujas raízes mais antigas podem estar fincadas no continente africano. Efetivamente, na África do Sul, há um intenso consumo hoje em dia de cabeça de boi, que parece ter considerável profundidade temporal. Contudo, esta é uma investigação apenas preliminar, a ser adensada em etnografias de grupos africanos e através de análises zooarqueológicas em sítios históricos com presença de escravos, de modo que se possa ter uma medida mais precisa da extensão e intensidade dessa prática no espaço e no tempo.

\section{REFERENCIAS}

Abreu, M. A. (2010), Geografia bistórica do Rio de Janeiro (1502-1700), Andrea Jakobsson Estúdio/Prefeitura do Município do Rio de Janeiro, Rio de Janeiro.

Bandeira, J., Lago, P. C. (2009), Debret e o Brasil: obra completa 1816 - 1831, Capivara, Rio de Janeiro.

Coaracy, V. (1988), Memórias da Cidade do Rio de Janeiro, Itatiaia-Edusp, Belo HorizonteSão Paulo. (Coleção Reconquista do Brasil, 2. a série, vol. 132).

Colley, S. (2006), "A preliminary beef meat cuts typology for nineteenth-century Sydney and some methodological issues", Australasian Historical Archaelogy 24: 47-54.

Debret, J. B. (1940), Viagem pitoresca e histórica ao Brasil, Tomo I (volumes I e II), Livraria Martins, São Paulo.

Mann, C. C., Hecht, S. (2012), “Terra de homens livres”, National Geographic, Ano 12, 145: 70-89.

Ruas, J. L., Lima, V. R. S., Santos, P. R. (1978), A culinária no litoral fluminense, Instituto Estadual do Patrimônio Cultural, Rio de Janeiro.

Tavares, G. C. (2012), A atuação dos Marchantes no Rio de Janeiro colonial. Estratégias de mercado e redes de sociabilidade no comércio de abastecimento de carne verde (17631808), Secretaria Municipal de Cultura-Arquivo Geral da Cidade do Rio de Janeiro, Rio de Janeiro. 
Vieira Fazenda, J. (2011a), “Antiqualhas e memórias do Rio de Janeiro". Revista do Instituto Histórico e Geográfico Brasileiro, Tomo 93, vol. 147 [1923] e vol. IV.

Vieira Fazenda, J. (2011b), “Antiqualhas e memórias do Rio de Janeiro”. Revista do Instituto Histórico e Geográfico Brasileiro, Tomo 95, vol. 149 [1924] e vol. V.

\section{WEBsites CONSULTADOS}

Canal Record TV Confresa, Culinária: Cabeça de vaca no tacho, 04/05/2013, Disponível em: <https://www.youtube.com/watch?v=kxMUGn3HwKM>, Acesso em: 8 jul.2015.

Canal de Wesley Andrade Silva, Cabeça de boi assada no chão, 17/07/2012, Disponível em: <https://www.youtube.com/watch?v=J4zjyGGBh0E>, Acesso em: 8 jul. 2015.

Globo.com, É Bem MT traz a tradicional Cabeça de Boi, 11/08/2012, Disponível em: < http://g1.globo.com/mato-grosso/videos/t/todos-os-videos/v/e-bem-mt-traza-tradicional-cabeca-de-boi/2083768/>, Acesso em: 16 jun. 2015.

SAPRAC, Comida típica, Disponível em: <https://saprac.wordpress.com/2008/11/12/ comida-tipica/>, Acesso em: 31 jul. 2015.

TocNotícias, Conheçam os heróis do Maranhão que com talento, força de vontade e superação, vão sobrevivendo no interior do estado, 04/06/2013, Disponível em: <www.tocnoticias. com.br/ler_noticia.php?idnoticia=477>, Acesso em: 18 jul. 2015. 